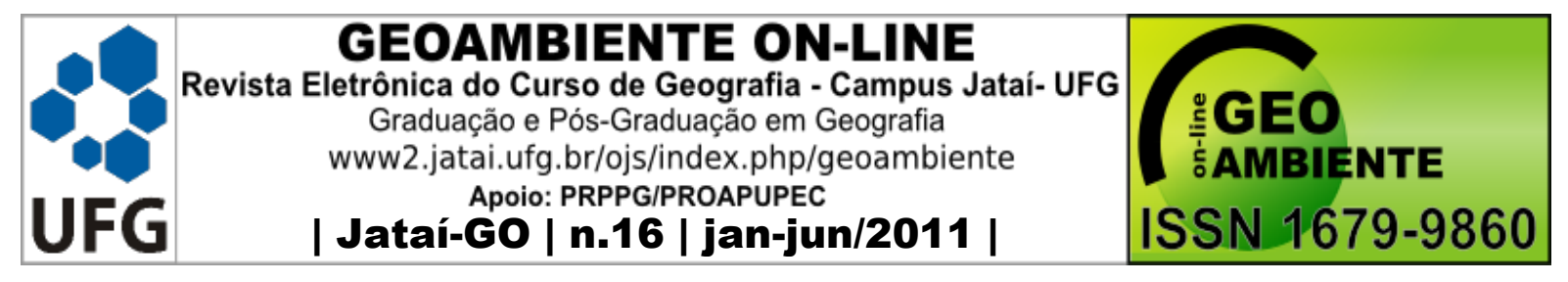

\title{
ANÁLISE ESPAÇO-TEMPORAL DA DINÂMICA DO ESPAÇO URBANO EM CONSEQUÊNCIA DA INDUSTRIALIZAÇÃO NO MUNICÍPIO DE TRÊS LAGOAS - MS - BRASIL
} Rafael Marques dos Santos', Ana Gabriela Bueno Melo de Carvalho²

(1- Universidade Estadual Paulista - Unesp - Deplan - Mestrando em Geografia/Bolsista CNPq, CEP 13506-900, Rio Claro - São Paulo - Brasil, geografia.rafael@gmail.com, 2Universidade Estadual Paulista - Unesp - Doutoranda em Geografia/Bolsista CNPq, CEP 13506-900, Rio Claro - São Paulo - Brasil, decarvalho.ag@gmail.com)

\section{Resumo}

O objetivo principal do trabalho é demonstrar e mapear a expansão do espaço urbano em decorrência da implantação de indústrias no município de Três Lagoas - MS. A metodologia adotada consistiu na revisão bibliográfica sobre a reprodução do espaço urbano, levantamento e análise de dados obtidos junto ao IBGE. Os procedimentos operacionais consistiu na elaboração de mapas de Uso do Solo a partir da imagem de satélite LANDSAT 5 TM (Land Remote Sensing Satellite), órbita 223 e ponto 74, bandas 3, 4 e 5 dos anos de 1990, 2000 e 2010. Utilizou-se do software SPRING® 5.0. (Instituto Nacional de Pesquisas Espaciais) e das etapas técnicas propostas pelo INPE para elaboração de mapas de uso do solo por meio de verossimilhança de pixel. Com o cruzamento do levantamento dos dados e a elaboração dos mapas de uso do solo de 1990, 2000 e 2010, pode-se constar-se a expansão urbana com a implantação da indústrias.

Palavras Chave: Três Lagoas. Espaço - temporal, Espaço urbano.

\section{ANALYSIS OF SPATIAL-TEMPORAL DYNAMICS OF URBAN SPACE AS A RESULT OF INDUSTRIALIZATION IN THE CITY OF TRÊS LAGOAS - MS - BRAZIL}

\footnotetext{
Artigo recebido para publicação em 03 de Fevereiro de 2011

Artigo aprovado para publicação em 18 de Junho de 2011
} 


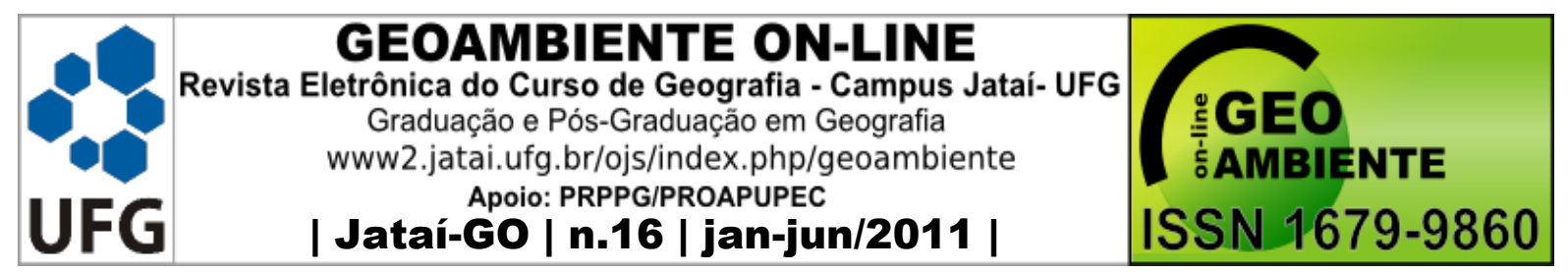

\section{Abstract}

The aim of this work is to demonstrate and map the expansion of urban areas due to the establishment of industries in the municipality of Três Lagoas - MS. The methodology consisted of literature review on the reproduction of urban space, survey and analysis of data obtained from the IBGE. Operating procedures consisted in mapping Land Use from LANDSAT 5 TM satellite imagery (Land Remote Sensing Satellite), orbit 223, item 74, bands 3, 4 and 5 of the 1990, 2000 and 2010. We used the software SPRING ${ }^{\circledR}$ 5.0. (National Institute for Space Research) and the steps proposed by INPE techniques for mapping land use through likelihood pixel. With the crossing of the data collection and processing of land use maps of 1990, 2000 and 2010 may be included to urban expansion with the establishment of industries.

Keywords: Três Lagoas. Spatial - tempotal. Urban space.

\section{ANÁLISIS DE LA DINÁMICA ESPACIO-TEMPORALES DEL ESPACIO URBANO COMO RESULTADO DE LA INDUSTRIALIZACIÓN EN LA CIUDAD DE LOS TRES LAGOS - MS - BRASIL}

\section{Resumen}

El objetivo de este trabajo es demostrar el mapa de la expansión de las zonas urbanas debido a la creación de industrias en el municipio de Três Lagoas - MS. La metodología consistió en revisión de la literatura sobre la reproducción del espacio urbano de la encuesta, y el análisis de los datos obtenidos del IBGE. Los procedimientos de operación consistió en la cartografía de uso de la tierra a partir de imágenes de satélite LANDSAT 5 TM (Satélite de Teleobservación Terrestre), la órbita 223, artículo 74, bandas 3, 4 y 5 del 1990, 2000 y 2010. Se utilizó el software de PRIMAVERA ® 5.0. (Instituto Nacional de Investigaciones Espaciales) y las medidas técnicas propuestas por el INPE para utilizar la asignación de tierras a través de píxeles de probabilidad. Con el paso de la recolección y procesamiento de datos de mapas de usos de suelo de 1990, 2000 y 2010 se pueden incluir para la expansión urbana, con el establecimiento de industrias.

Palabras clave: Tres Lagos. Tiempo - Espacio, Espacio Urbano. 


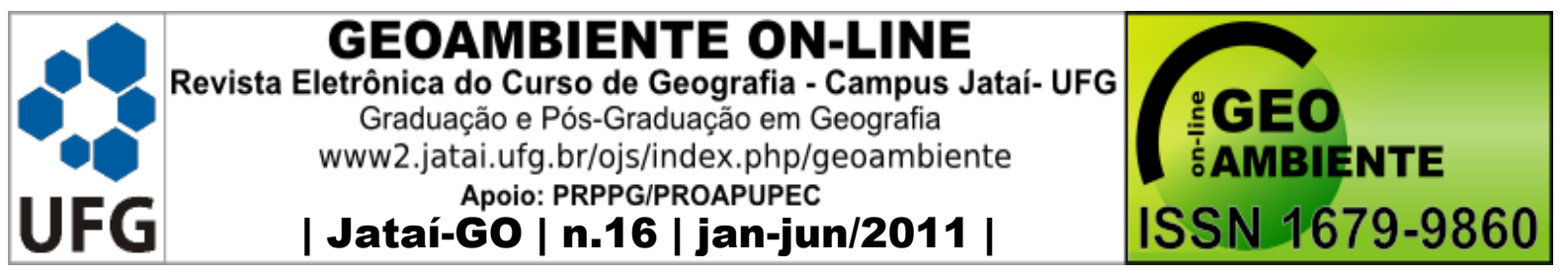

\section{Introdução}

O município de Três Lagoas, segundo IBGE (2010) se localiza no Estado do Mato Grosso do Sul na região leste do estado entre as coordenadas $20^{\circ} 45^{\prime} 04^{\prime \prime} \mathrm{S}$ e $51^{\circ} 40^{\prime} 42^{\prime \prime} \mathrm{W}$ (figura 1), conta um pouco mais de 98 mil habitantes, e é a $4^{\text {a }}$ maior cidade do estado.

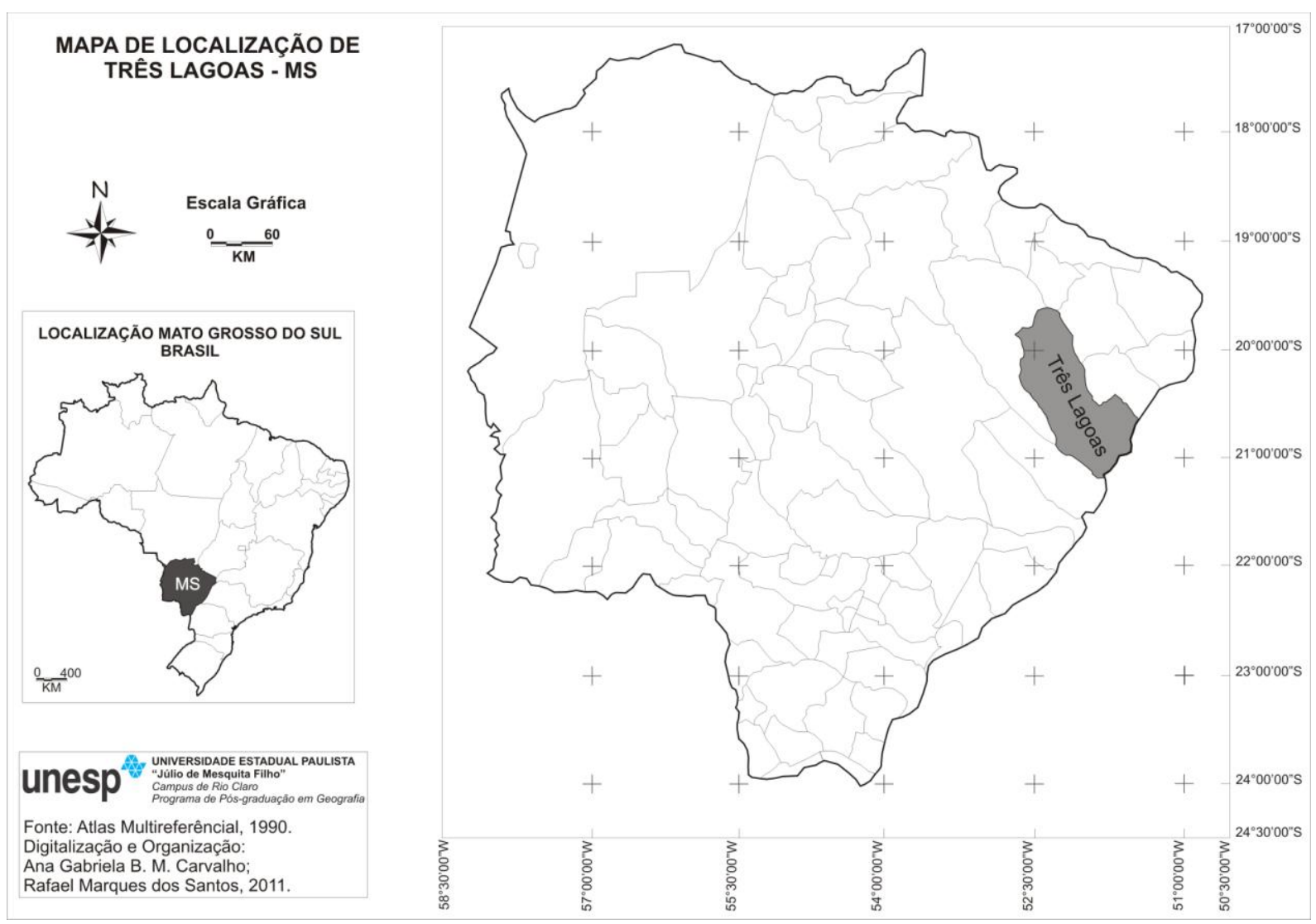

Figura 1: Localização do município de Três Lagoas/MS.

Com um vertiginoso crescimento econômico e demográfico, Três Lagoas se destaca regionalmente pela capacidade de oferta de bens e serviços, consequentemente influencia o redirecionamento do fluxo de pessoas como um promissor mercado de trabalho. (ARANHASILVA et al, 2009).

Sendo assim, este artigo teve por objetivo caracterizar a dinâmica de produção do espaço urbano da cidade de Três Lagoas advindo do processo de industrialização iniciado em 1997. Para isto, realizou-se o mapeamento histórico do crescimento da malha urbana em três cenários distintos: em 1990, período anterior a instalação das primeiras indústrias; no ano de 


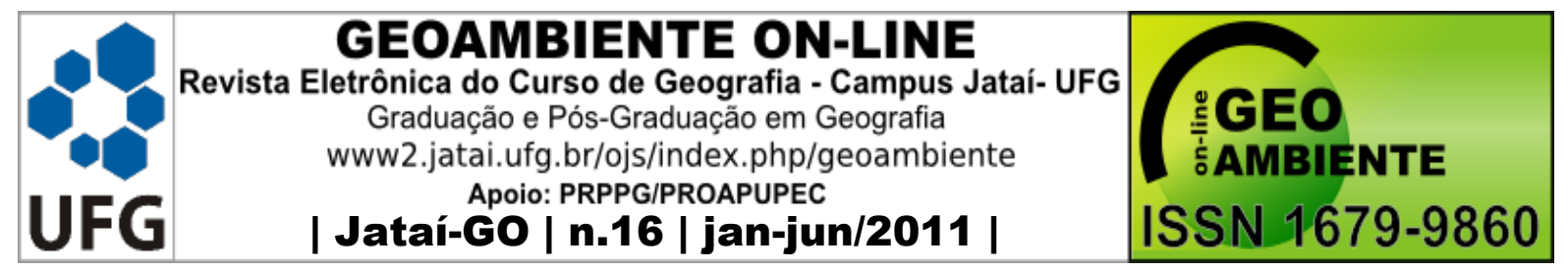

2000, no início do processo de industrialização; e 2010, quando a industrialização acontece de maneira explosiva.

No contexto, essas geotecnologias são compostas por um conjunto de tecnologias para coleta, processamento, análise e disponibilização de informação com referencia geográfica, por exemplo, as imagens de satélite (FERREIRA, 2008). Sua utilização se faz cada vez mais presente nas interpretações de estudos ambientais, pois viabiliza um melhor monitoramento da área sem que haja contato direto com a mesma (GONZAGA, 2008).

Considerou-se que o espaço geográfico é o espaço ocupado e organizado pelas sociedades humanas (OLIVEIRA, 2006). Portanto, essas relações são antes de tudo relações de trabalho dentro do processo produtivo geral da sociedade (SANTOS, 1996). Sendo que, a industrialização é um fenômeno concentrado no espaço enquanto produto da aglomeração de meios de produção, mão-de-obra, capitais e mercadorias (OLIVEIRA, 2006).

\section{Três Lagoas (MS): Histórico de Ocupação}

Segundo Cattanio (apud MILANI, 2009), a ocupação da cidade de Três Lagoas aconteceu em dois momentos distintos, anterior e posterior à chegada da Estrada de Ferro Noroeste Brasil. Três Lagoas foi o primeiro povoado, no estado do então Mato Grosso, que se formou em decorrência da estrada de ferro da NOB (Noroeste do Brasil). Em 1910 a ferrovia passou por Três Lagoas e em 1914 foi entregue o trecho Bauru/SP-Porto Esperança/MT.

O local escolhido pelos trabalhadores da construção da estrada de ferro para se instalarem se localizou nas proximidades da Lagoa Maior (LORENZ-SILVA, 2004). O local recebeu o nome de Formigueiro (bairro Santa Luzia), e serviu também para alojar a população dispersa advinda da área pastoril, que servia como mão de obra não qualificada (ARANHASILVA, 1992).

No período (1910-1912), a ferrovia modelou a paisagem urbana de Três Lagoas.

As obras da ferrovia na região terminaram em 1910 e foi inaugurada a estação ferroviária em local distante do ponto de concentração formado anteriormente, o que motivou a transferência do equipamento urbano.

A ponte Francisco de Sá só foi concluída em 12 de outubro de 1926, possibilitando o fluxo normal das composições. Até então, a travessia era feita através de balsas (LORENZ- 


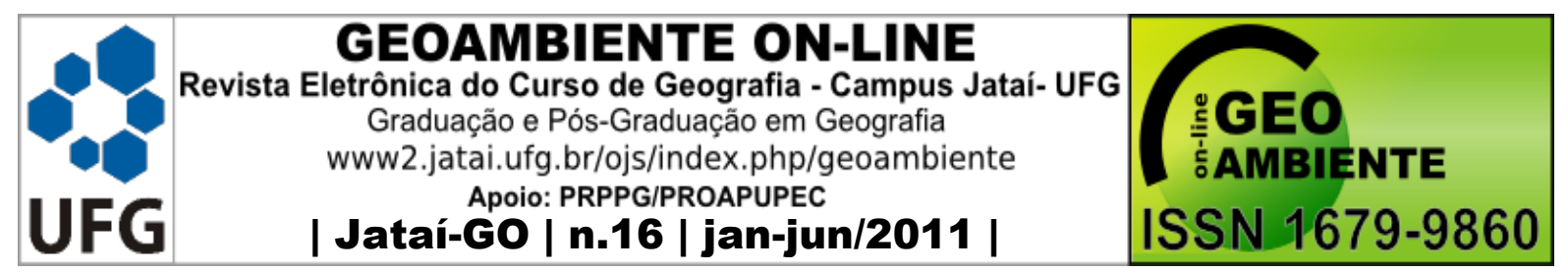

SILVA, 2004). Esta particularidade justificou a formação de uma população flutuante em Três Lagoas, que pernoitavam a fim de cruzarem o rio Paraná com o dia claro. "[...] $\mathrm{O}$ aumento do número de pessoas incentivou a instalação de comércios e serviços, é dessa organização que derivou a área central no espaço intra-urbano de Três Lagoas" (ARANHASILVA, 1992).

Com o adensamento populacional, a Resolução Estadual no 820/10/1920 elevou a vila para a condição de cidade e promulgou-se em 15/06/1918 a Lei $\mathrm{n}^{\circ} 752$, que criou a comarca de Três Lagoas (MILANI, 2009).

Em 1912, logo após a doação da área para a criação da cidade de Três Lagoas, demarcaram 35 quarteirões, com $10.000 \mathrm{~m}^{2}$ cada, delimitados por ruas de $30 \mathrm{~m}$ e circundados por avenidas de $50 \mathrm{~m}$ de largura, os quarteirões foram divididos em lotes de 25 x $50 \mathrm{~m}$, denominados de lotes urbanos, e vendidos pela Prefeitura a terceiros com pretensões de construírem (CATTANIO, 1976 apud MILANI, 2009). A área remanescente foi dividida em lotes de $48.000 \mathrm{~m}^{2}$, os lotes suburbanos, os quais formaram as chácaras que deveriam abastecer a cidade com produtos horti-granjeiros (CATTANIO, 1976 apud MILANI, 2009).

A partir das décadas de 1970, 1980 e inicio de 1990, Três Lagoas passou por um novo processo de (re)estruturação da malha urbana, novos loteamentos se formaram na porção sul e sudeste redirecionando o crescimento da cidade para essa direção. A partir de 1997 houve a intensificação do fluxo de indústrias para Três Lagoas, motivadas pelos incentivos fiscais oferecidos pelos governos estadual e municipal, aumentando assim a demanda por moradia, infra-estrutura e serviços (MILANI, 2009).

\section{Três Lagoas (MS): A industrialização}

A economia do município de Três Lagoas foi baseada na pecuária até 1997, quando através de incentivos fiscais e sua localização estratégica na divisa com o estado de São Paulo, o sistema de transporte multimodal viabilizado pela BR-262, a ferrovia América Latina Logística e navegação fluvial Tietê-Paraná, têm motivado diversas indústrias. A abundância de energia elétrica e facilidade para contratação de mão-de-obra disponível ou oriunda de outras regiões facilitaram a consolidação de um pólo industrial sul-mato-grossense. (DADALTO et al, 2009). 


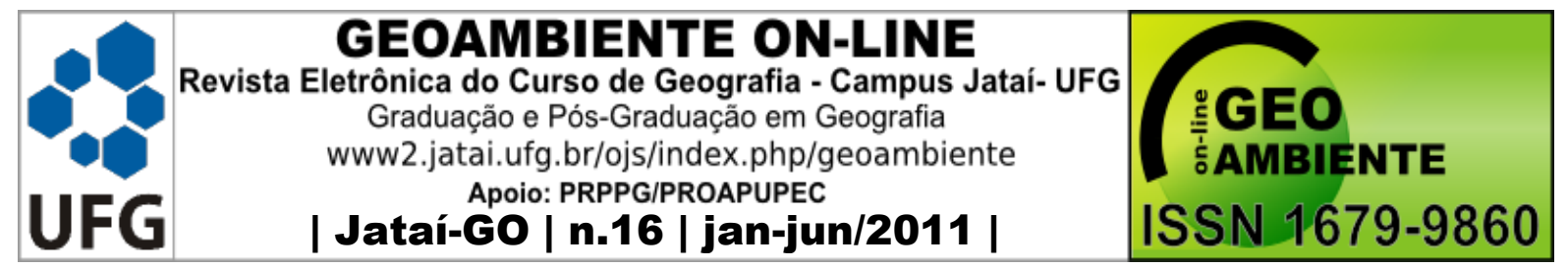

procurando sempre um local estratégico, visando sempre o lucro, fragmentando e descentralização a malha urbana e a sociedade influenciada.

\section{Discussão Crítica}

Aranha-Silva; Silva; Leal (2006) argumenta que se deve analisar inicialmente o fenômeno urbano em suas formas e estruturas, para só depois compreender as relações sócioespaciais.

Segundo Lefebvre (1973), "Ciência do Espaço? Não. Conhecimento (teoria) da produção do espaço. A ciência do espaço (matemática, física, etc.) é do domínio da lógica, da teoria dos conjuntos e coesões, sistemas e coerências. O conhecimento do processo produtivo, que faz entrar na existência social este produto que é o mais geral de todos - o espaço - é do domínio do pensamento dialético, que lhe apreende as contradições. É neste espaço dialetizado (conflitual) que se consuma a reprodução das relações de produção. É este espaço que produz a reprodução das relações de produção, introduzindo nelas contradições múltiplas, vindas ou não do tempo histórico."

Para Lefebvre (2004), o espaço urbano é o resultado de uma história que deve ser concebida com a atividade de "agentes" ou "atores" sociais, de "sujeitos" coletivos que operam por impulsos sucessivos, projetam e modelam de modo descontínuo extensões de espaço.

A cidade adquire um valor conceitual de extrema relevância para fundamentação teórica da concepção da 'produção do espaço e da reprodução das relações sociais. A cidade revela, em certo sentido, a unidade das relações capital-trabalho e da história da aventura humana no domínio sobre a natureza. De acordo com o autor, a cidade "é um espaço, um intermediário, uma mediação, um meio, mais vasto dos meios, o mais importante. A transformação da natureza e da terra implica um outro lugar, um outro ambiente: a cidade" (LEFEBVRE, 2001).

Sendo Assim, o espaço urbano é fragmentado e articulado, como um reflexo de condicionantes sociais, um conjunto de símbolos e campo de lutas. É assim a própria sociedade em uma de suas dimensões, aquela mais aparente, materializada nas formas espaciais (CORRÊA, 1995). Portanto, o território é uma extensão das relações humanas, é onde se encontram suas raízes, sua história, seus ancestrais. Primeiramente, como valor de 


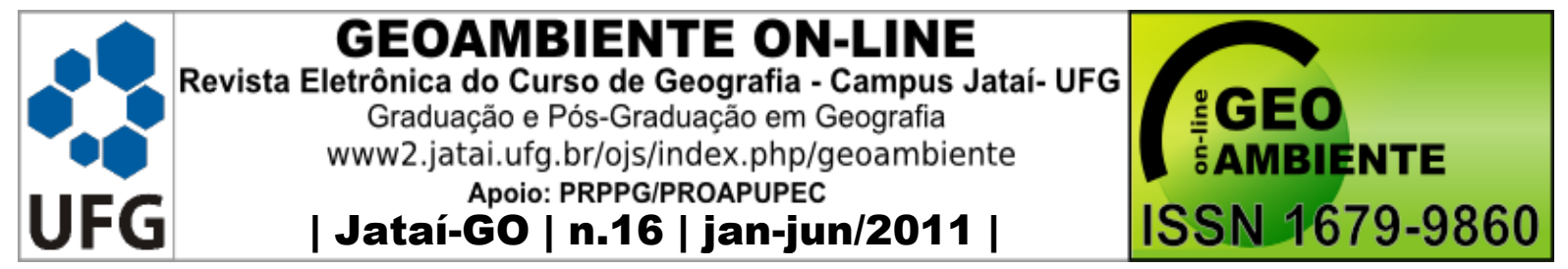

uso, o território é um forte elo de identidade; e posteriormente, como valor de troca, demonstra a apropriação (DADALTO et al, 2009).

\section{Metodologia}

\subsection{Materiais}

Elaborou-se os mapas a partir de imagem de satélite LANDSAT 5 TM (Land Remote Sensing Satellite - Thematic Mapper), órbita 223 e ponto 74, bandas 3, 4 e 5 dos anos de 1990, 2000 e 2010. Utilizou-se do software SPRING ${ }^{\circledR}$ 5.0. (Instituto Nacional de Pesquisas Espaciais) em uma primeira etapa e posteriormente o software Global Mapper ${ }^{\circledR}$ para uma reinterpretação visual dos resultados obtidos.

\subsection{Procedimentos metodológicos}

Os procedimentos metodológicos pautaram-se no levantamento bibliográfico pertinente e da formulação de uma série histórica de mapas de uso e ocupação do solo da cidade de Três Lagoas.

As técnicas para elaboração dos mapas de uso do solo pautou-se em duas etapas propostas pelo INPE: Pré-processamento de imagens através da elaboração da melhor composição colorida e realce, e posteriormente o registro das imagens; e o pós-processamento digital de imagens, com a classificação supervisionada por meio de verossimilhança de pixel com o classificador MaxVer e a elaboração do mapa temático.

\section{Resultados e discussões}

Criaram-se cinco classes de mapeamento: Área rural, drenagem, vegetação, urbano densamente ocupado e urbano em processo de ocupação. Os resultados revelaram sempre uma área central mais densamente ocupada, sendo que este processo de densidade ocupacional vai diminuindo para as extremidades.

No entanto, devido ao núcleo urbano de Três Lagoas possuir muitas áreas vagas, e sem muita cobertura do solo, a reflectância espectral muitas vezes foi confundida com a área rural. Neste sentindo, posterior ao mapeamento realizado pelo SPRING, os dados foram reorganizados por meio de interpretação visual e agrupamento de classes de acordo com uma 


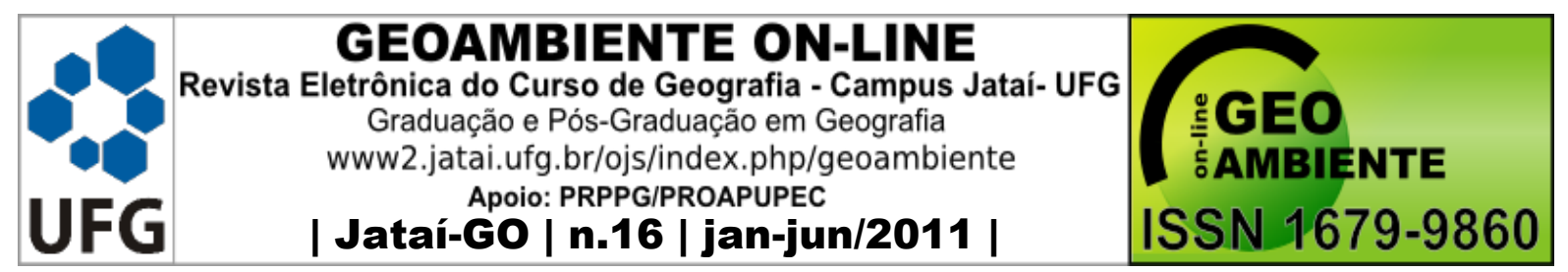

chave interpretativa em níveis de cinza elaborada pelos autores com o uso do software Global Mapper com o intuito de uma melhor visualização dos resultados (figura 3).

A chave de interpretação foi baseada de acordo com a resposta visual obtida em ambiente SIG: Área densamente ocupada - A resposta espectral foi obtida principalmente devido a alta concentração de superfície ocupada e a presença de ruas asfaltadas; Área urbanizada - A resposta espectral foi obtida pela presença de asfalto, no entanto, a concentração urbana é menor que a anterior; Área pouco urbanizada - A resposta espectral foi alcançada devido a falta de cobertura nas vias públicas e a concentração de área urbanizada; Área em processo de urbanização - A resposta espectral corresponde a uma área sem asfalto nas vias públicas, e a baixa ocupação. Muitas vezes, esta situação foi respondida pelo software SPRING como área rural; Área rural - Área fora do núcleo central. 


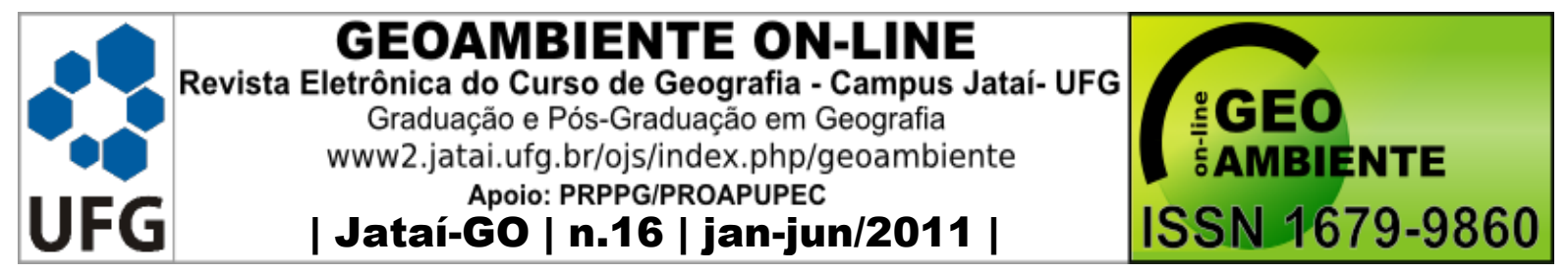
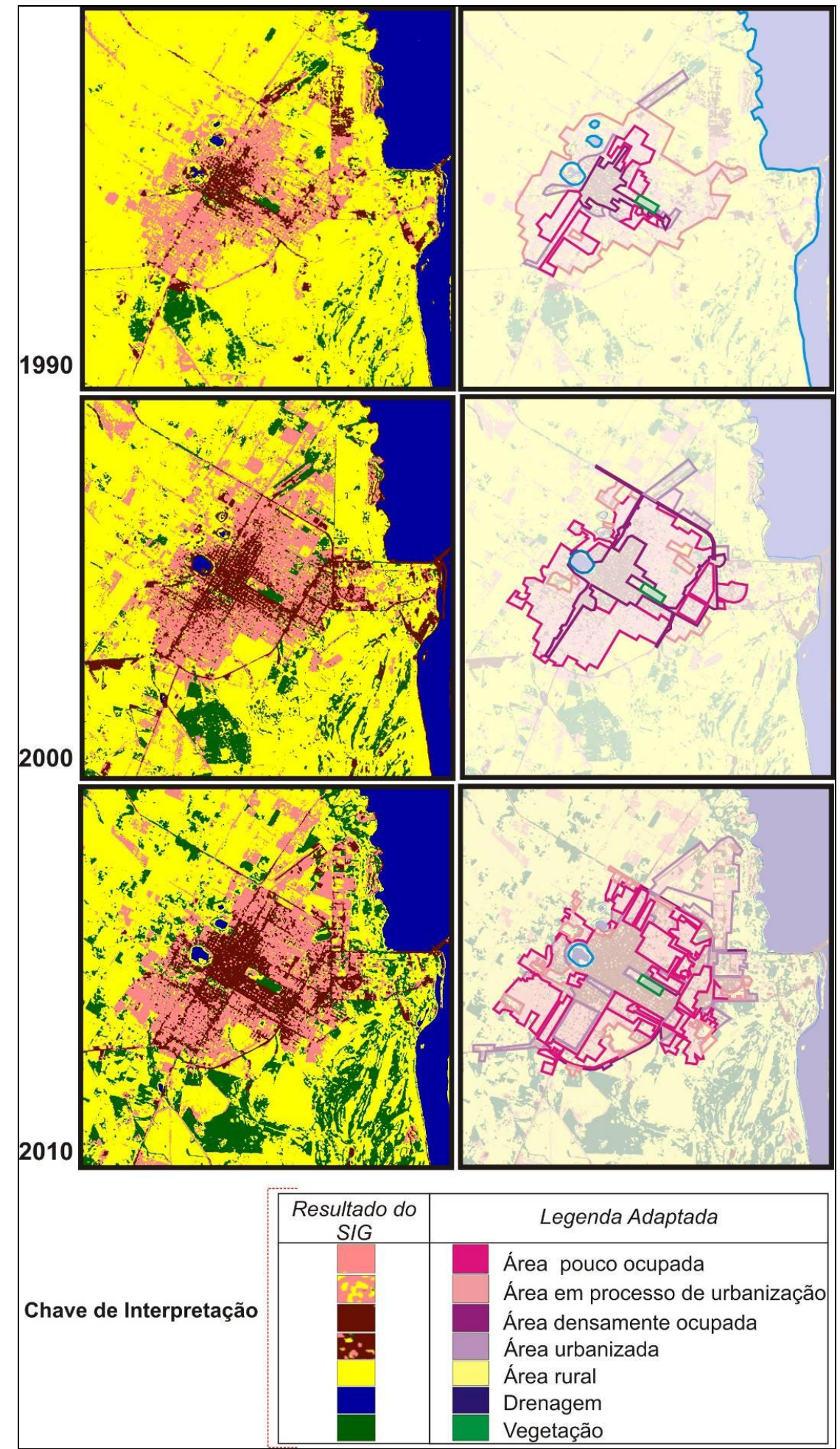

Figura 3: Resultado obtido pelo SPRING e reorganização dos dados.

Os resultados alcançados basearam-se na confecção de três mapas Análise Espaço Temporal do urbano no município de Três Lagoas- MS, (figura 4). Esses mapas nortearam as 


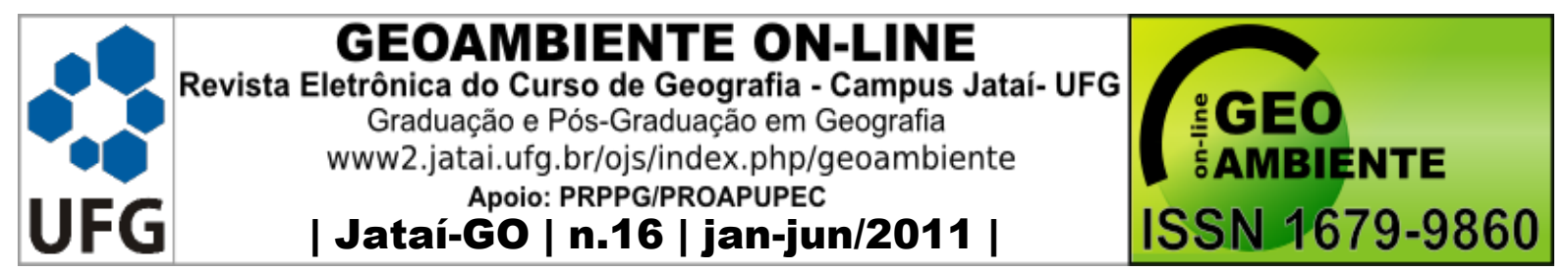

discussões a cerca da dinâmica espacial do crescimento/(re)produção urbano frente ao processo de industrialização ocorrido no município nessas últimas décadas.

O mapa referente a 1990 revela um urbano mais concentrado na área central, sem distrito industrial. Vale salientar que, segundo Milani (2009), foi a partir da década de 1980 e início de 1990, que Três Lagoas passou por um processo de (re)produção do seu espaço urbano, quando os novos loteamentos se consolidaram na porção sul e sudeste e redirecionaram o crescimento da cidade para essa direção.

Devido a chegada do processo industrial em 1997, no mapa dois é possível observar uma melhor distribuição espacial da urbanização. Salienta-se que, a partir de 1997 houve um aumento da demanda por moradia, infra-estrutura e serviços decorrentes da intensificação do fluxo de indústrias para

Três Lagoas, motivadas pelos incentivos fiscais oferecidos pelos governos estadual e municipal (MILANI, 2009). Aranha-Silva; Silva; Leal (2006) elucidam que:

A expansão do tecido urbano se intensificou com novos loteamentos e edificações e adensou-se por meio da verticalização; por conseguinte, aumentou o fluxo de pessoas, mercadorias e de veículos que requereu ampliação da malha viária, infra-estrutura, equipamentos, serviços públicos e a revitalização de prédios e praças.

O mapa três (ocupação em 2010) revela um amplo distrito industrial, localizado ao nordeste do núcleo urbano. O uso do solo neste mapa encontra-se mais mesclado por diferentes classes de ocupação.

A (re) produção do espaço urbano em detrimento com a chegada do capital financeiro instalado nas indústrias provindas de diferentes estados do país pode ser observado na figura 5 . 


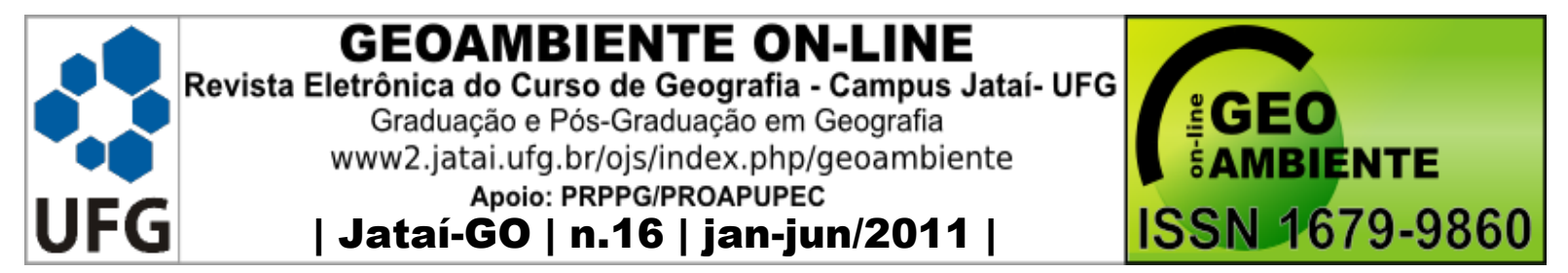

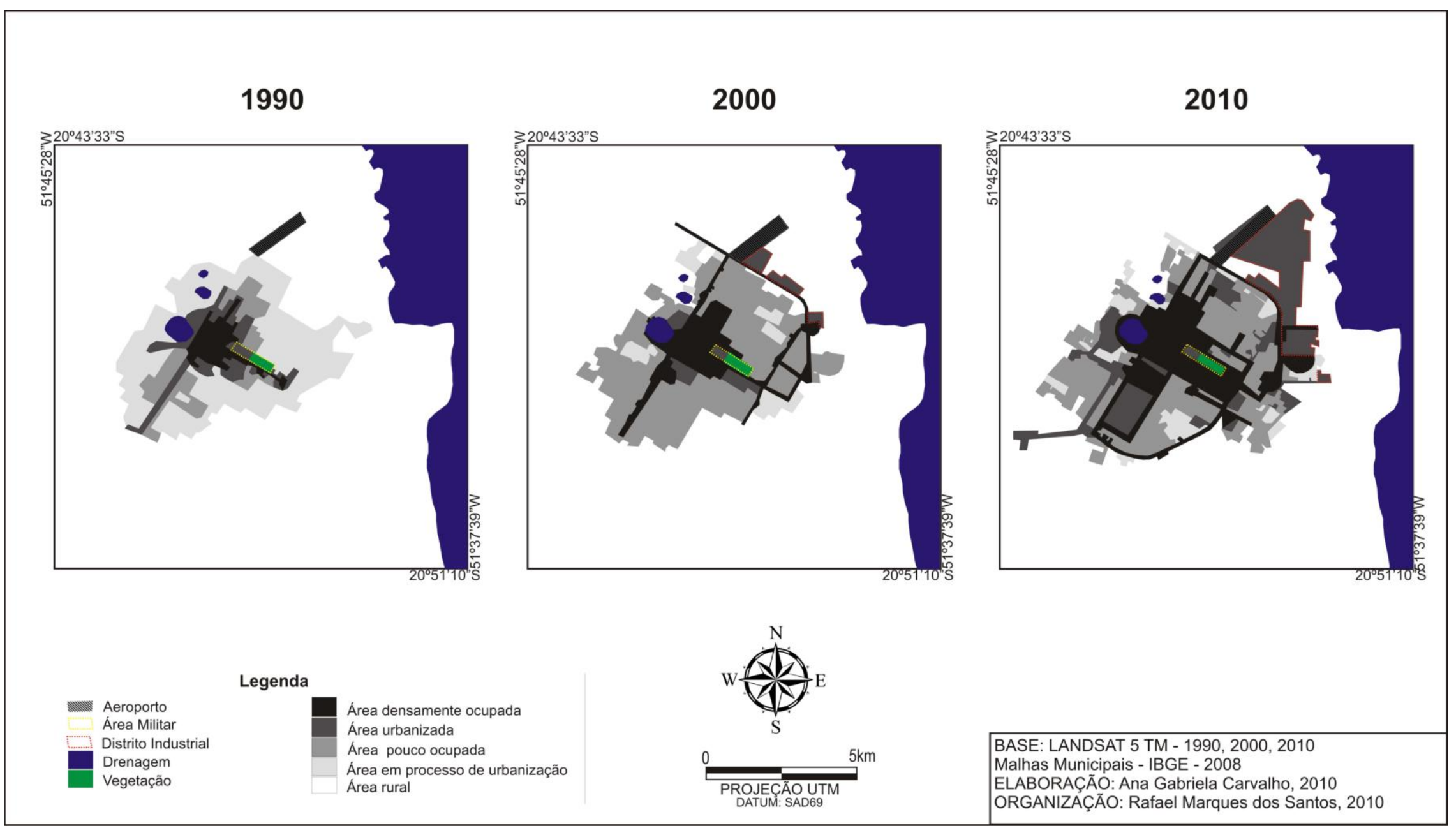

Figura 4: Análise Espaço - Temporal do urbano no município de Três Lagoas- MS. 


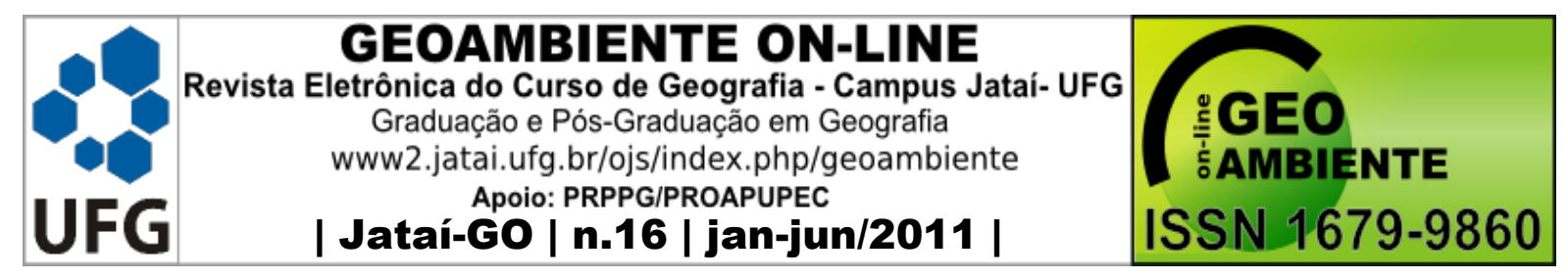

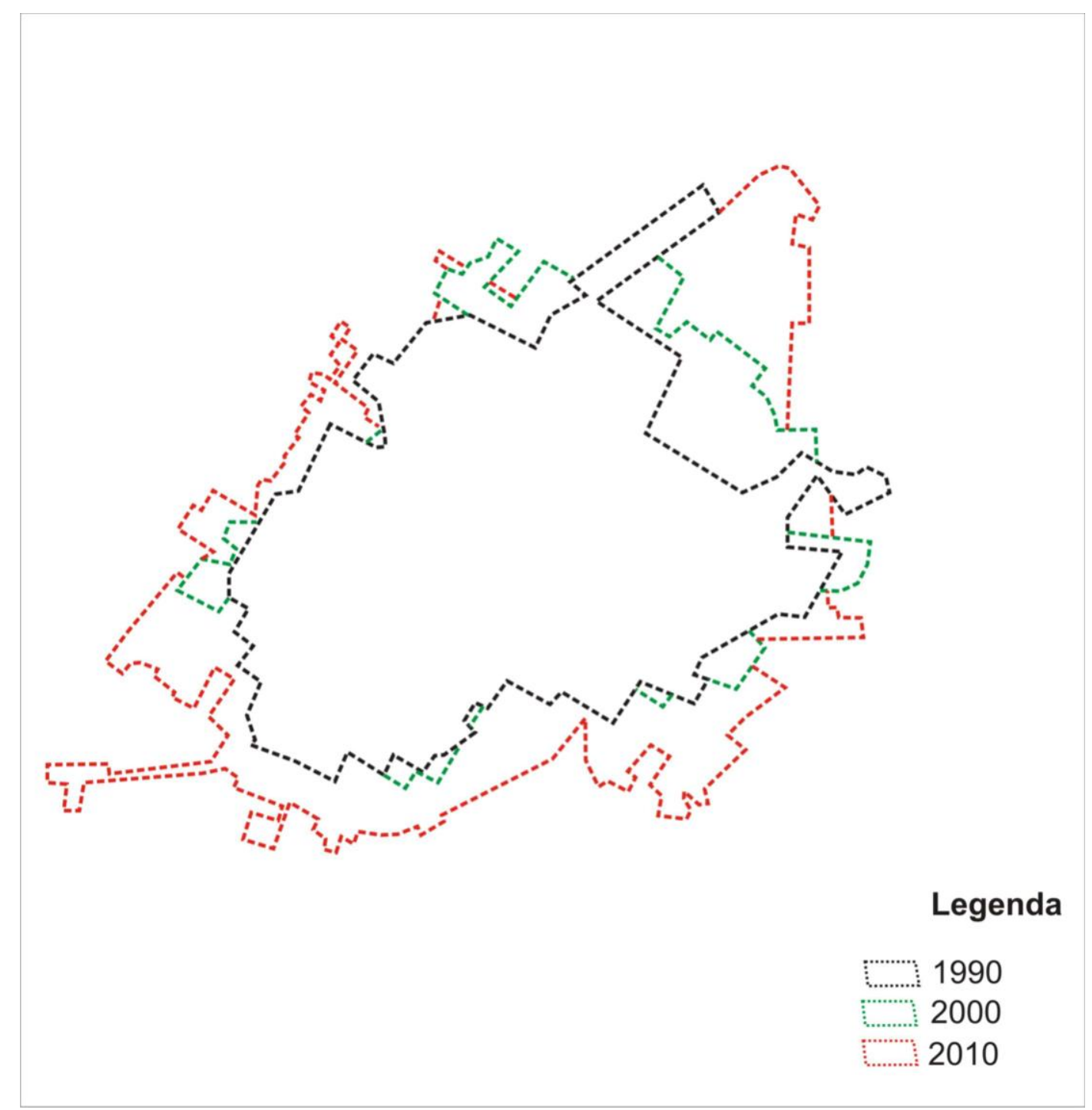

Figura 5: Croqui esquemático: Crescimento Espacial- Temporal do urbano em Três Lagoas/MS.

Observa-se que o crescimento espacial ocorrido em 2000 se situou mais em direção nordeste, nas proximidades das alocações dos distritos industriais. Em 2010, este crescimento aconteceu mais de maneira fragmentada, principalmente devido a implantação de uma indústria de papel e celulose de grande porte distanciada do centro urbano. Esta mesma indústria investiu em loteamentos e construções em espaços vazios urbanos, provavelmente devido ao valor mais baixo dos terrenos. Ainda em 2010, observa-se a ampliação do distrito industrial a nordeste da cidade. 


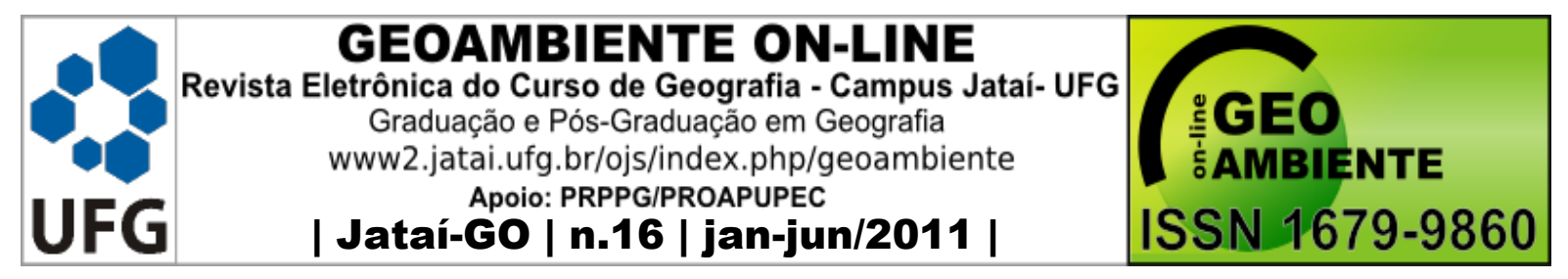

Atualmente, segundo Milani (2009), a cidades de Três Lagoas, por apresentar nos últimos 5 anos um elevado crescimento demográfico e industrial, passa por um momento de transição de uma cidade pequena para uma cidade média, pela sua importância sócioeconômica no contexto regional e nacional. Segundo a autora, o que define uma cidade média não é apenas o número populacional, mais sim a função que ela exerce entre os municípios vizinhos, no oferecimento de serviços diversificados, que atraem pessoas oriundas da região que a cidade está inserida, assim ela exerce um papel de centro regional, e obtém uma área de influência.

\section{Considerações Finais}

A pesquisa revelou que cidade de Três Lagoas;MS (Brasil) passa por um processo de reestruturação sócio-espacial e está em transição, ou seja, ganha características de cidade média, em decorrência da sua recente fase de industrialização, pelo seu crescimento econômico (aumento do PIB), pelo aumento demográfico, pela segmentação espacial formando novas centralidades, por conseguinte torna-se um pólo regional.

Este processo de reprodução do espaço que ocorre de forma dinâmica, podemos perceber com a análise espaço-temporal exemplificado nos mapas de forma linear dos anos de 1990, 2000 e 2010, uma grande modificação no arranjo de sua malha urbana, em decorrência das necessidades impostas com a inserção do capital pela novas indústrias. Ocorrendo um inchaço urbano em determinadas áreas de interesse pela industrias, posteriormente a descentralização e fragmentação do urbano.

Esta descentralização e fragmentação do espaço urbano ocorre posteriormente ao ano de 1997, ano este da chegada das indústrias, fazendo com que ocorra a (re)produção do espaço urbano em virtude das estratégias locacionais, para maximização de seus lucros.

\section{Bibliografias}

ARANHA SILVA, E. Três Lagoas: uma interpretação do rural com o urbano. Presidente Prudente: UNESP, 1992. (Dissertação de Mestrado). 


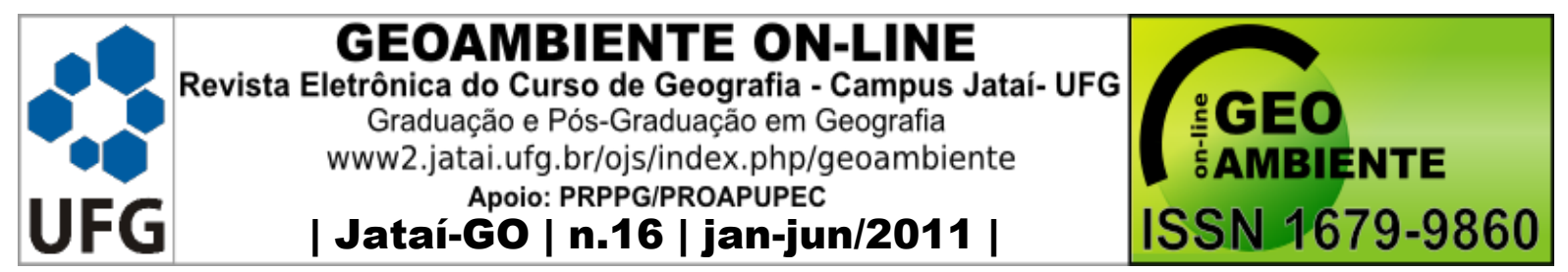

ARANHA SILVA, E.; SILVA, D. R. A.; LEAL, F. V. A. A (re) estruturação espacial urbana de Três Lagoas-MS. In: II Simpósio Internacional sobre cidades médias. Universidade Federal de Uberlândia, 2006. Anais... Uberlândia, CD-R. (Artigo completo)

ARANHA-SILVA, E.; CHAVES, D. D.; CLEMENTE, R. H.; SANTOS, B. M.; MILANI, P. H. Três Lagoas em Mato Grosso do Sul (Brasil) e sua inserção na hierarquia urbana regional. Anais... $12^{\circ}$ Encontro de Geógrafos da América Latina: Montevideo - Uruguay, 2009.

CÔRREA, R. L. O espaço urbano. São Paulo: Ática,1995

DADALTO, W. C.; ARANHA-SILVA, E.; LEMES, M. S.; FLORES, M. A.; LEAL, G. Q.; ALVES-SILVA, C. A.; SILVA, L. C. A dinâmica sócio-espacial de três lagoas em mato grosso do sul (brasil) e a importância dos meios de hospedagem para o turismo de negócios. Anais... 12 $2^{\circ}$ Encontro de Geógrafos da América Latina: Montevideo - Uruguay, 2009.

FERREIRA, C.C. Geoprocessamento e sensoriamento remoto: processamento de imagens orbitais de sensores passivos (CCD e TM) e Ativos (SRTM) como subsidio para o gerenciamento da Bacia Hidrográfica das Pitangueiras/ SP. 2008. 86 f. Trabalho de Conclusão de Curso (Graduação em Geografia) - Universidade Federal de Mato Grosso do Sul - UFMS, Três Lagoas, 2008.

GONZAGA, M. L. O uso de geotecnologias na análise da dinâmica ambiental da bacia hidrográfica do Córrego Dom Tomaz - Três Lagoas/MS. 2008. 68 f. Trabalho de

Conclusão de Curso (Graduação em Geografia) - Universidade Federal de Mato Grosso do Sul - UFMS, Três Lagoas, 2008.

INSTITUTO BRASILEIRO DE GEOGRAFIA E ESTATÍSTICA - IBGE. Produto Interno Bruto dos Municípios. [S.1.: s.n.], 2008.

INSTITUTO BRASILEIRO DE GEOGRAFIA E ESTATÍSTICA - IBGE. Censo: contagem da população 2010. [S.1.: s.n.], 2010.

LEFEBVRE, H. A Reprodução das Relações de Produção. Tradução: Antonio Ribeiro e M. do Amaral. Porto (Portugal): Publicações Escorpião - Cadernos O Homem e a Sociedade, 1973. $115 \mathrm{p}$.

LEFEBVRE, H. A Cidade do Capital. Tradução: Maria H. R. Ramos; Marilena Jamur. Rio de Janeiro: DP\&A, 2001. 


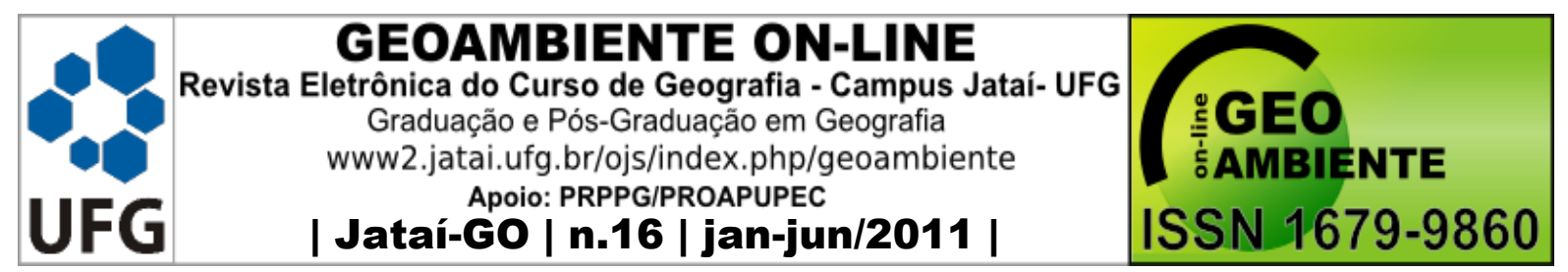

LEFEBVRE, H. A revolução urbana. Belo Horizonte: Ed. UFMG, 2004.

LORENZ-SILVA, J. L. O espongilito de Três Lagoas/MS. Registro e caracterização com ênfase em Micropaleontologia. Universidade do Vale do Rio dos Sinos - UNISINOS, UFMS - CAPES/MEC, 2004. Tese (Doutorado em Geologia)

MILANI, P. H. Centralidade urbana: um estudo do centro principal de Três Lagoas-MS. Trabalho Orientado de Geografia. Três Lagoas: UFMS/CPTL, 2009. (Trabalho de Graduação).

OLIVEIRA, P.. As relações entre as indústrias de Três Lagoas no contexto de territorialidade: Um estudo com perspectivas de desenvolvimento local. Campo Grande: UCDB, 2006. Dissertação de mestrado.

SANTOS, M. A natureza do espaço: técnica e tempo, razão e emoção. 3. ed. São Paulo: Hucitec, 1996. 